\title{
Effect of Payments for Disease Specific Care on Poverty Estimates in Nepal
}

\author{
Shiva Raj Adhikari, PhD \\ Associate Professor of Economics, \\ Department of Economics, Patan Multiple campus \\ Tribhuvan University, Nepal
}

\begin{abstract}
The popular poverty estimation method follows the cost of basic needs approach through estimation of poverty line. Health care is a basic necessity of life, as important as food, shelter, and clothing; however, current practice of estimating poverty indicators in Nepal does not capture the basic health care cost. Not accounted of out of pocket payment for health care into the poverty estimation could give a misleading picture of trends in poverty over time. Ignoring health care costs altogether can result in misclassifying which households or individuals are in the greatest need. Therefore, the paper estimated the revised poverty statistics with explicitly accounting for basic health care needs along with other basic needs such as food, clothing, and shelter by utilizing the Nepal living standard surveys(2010/11) data. The paper used the Foster, Greer and Thorbecke (FGT) poverty estimation method to estimate hidden or underestimated poverty before and after accounting health care payment. The results show that official poverty statistics are significantly underestimated while incorporating basic health care cost in the estimation of poverty statistics in Nepal. Out of pocket payments for health care of different diseases have different impoverishment impacts in terms of incidence and intensity of poverty. Higher average costs of health care cause higher impoverishment impacts. This paper indicates that incidence of poverty is underestimated by almost 4 percentage point and intensity of poverty is underestimated by 0.29 percent based on official estimation of poverty.
\end{abstract}

Key words: health care cost, hidden poverty, Nepal

\section{INTRODUCTION}

The Sustainable Development Goals (SDGs) are a universal agreement to end poverty in all its dimensions by 2030. The 17 SDGs are comprised of 169 targets and the attainments of these targets are measured through a set of 230 indicators (UN, 2015a). There may not be possible to achieve just one Goal; rather we have to achieve all of them, which are called the characteristics of 'integration by synergy' (UN, 2015b). Breaking cycles of poverty is a key cross-cutting initiative that builds on the synergies of the SDGs.Therefore, the SDGs have placed poverty eradication at the top of the agenda. Nepal has made a considerable achievement by reducing the number of people living in extreme poverty (NPC, 2017).However, current practice of 
measuring poverty in Nepal, similar to other low income countries, does not capture health care cost. Not accounted of out of pocket payment (OOP) for health care into the poverty estimation could give a misleadingpicture of trends in poverty over time (Van Doorslaer et al, 2006).On the other hand, due to health care cost, many poor people have to borrow money with high interest rate or to sell assets or to finance OOP for health care (Adhikari et al, 2009; Van Doorslaer et al, 2006). National Academy of Sciences panel in the USA and some other studies have recommended to adjusting the OOP for health care while estimating poverty (Short and Garner, 2002). There are many reasons for incorporating health care needs into a revised measure of poverty. Ignoring health care costs altogether can result in misclassifying which households or individuals are in the greatest need. Therefore, the paper estimated the revised poverty indicators with explicitly accounting for basic health care needs along with other basic needs such as food, clothing, and shelter.

The literature confirmed that OOP for health care can cause a low-income household to feelimpoverished even though the official definition of poverty indicates that they are not poor (Saksena et al, 2014). The paper thereforeseeks to estimate the hidden (or underestimated) poverty due to not accounting health care cost while estimating the official poverty statistics in Nepal. The estimated poverty can be interpreted as impoverishment impact of OOP for health care. This is estimated by computingthe percentage of individuals below the poverty line before and after netting out OOP for health care from household consumption.

The paper focuses to estimate impoverishment impacts of OOP for health care of acute and chronic illness by utilizing the data from national representative survey; Nepal living standards survey (NLSS) 2010/11 (CBS, 2011a).The stock of information on disease specific impoverishment impact is very useful for policy makers to design disease wise financial protection strategies for the country; however, very limited evidence on disease specific impoverishing impact is available in the literature (Hamid et al, 2014).

\section{METHODS AND MATERIALS}

In the literature, there are huge debates on measuring poverty (Anand, et al 2010). Different types of poverty such as income poverty, multidimensional poverty, and human poverty among others are in practice. The paper focuses on the monetary dimension of well-being that officially accepted in the various government documents such as development plans, economic surveys. Central Bureau of Statistics, the government of Nepal has used the consumption as the indicator of well-being. The variability and unpredictability of health expenditures makes it extremely difficult to incorporate them in a poverty line. The paper, to measure the hidden poverty, focuses on available resources to the household after deducting OOP for health care from household consumption as suggested in $\mathrm{O}^{\prime}$ Donnel, (2008). 
The official poverty line, NRs 19261,defined by CBS (2011b) for survey yearis used in this analysis. The paper used similar method suggested byVan Doorslaer et al (2006) that informs on the marginal effect of OOP for health care on poverty and its impact on household wellbeing. It is assumed that future health risk and past OOP for health care is closely related. Therefore, the household may feel impoverished the result of the expectation of future health expenses. Thus, Hidden poverty is estimated by comparing the incidence and intensity of poverty before and after netting out OOP for health care from per capita consumption.

The paper uses the Foster, Greer and Thorbecke (FGT) poverty estimation method that is used by CBS and the equation for calculating the FGT index is provided below (Chaubey, 1995):

Poverty index $=\frac{1}{N} \sum_{i=1}^{n}\left[\frac{P_{L}-Y_{P}}{P_{L}}\right]^{\lambda}$

where, $\mathrm{P}_{\mathrm{L}}=$ the poverty line income (threshold); $\mathrm{Y}_{\mathrm{Pi}}=$ below poverty line income. Values for $\lambda=0,1$, and 2, gives incidence, intensity and severity of poverty respectively. The index is sensitive to changes in income when $\lambda>0$, and to the transfer to income when $\lambda>1$. Incidence measures the proportion of the population that is poor. The poverty intensity expresses the gap between poverty line income and income of below poverty line. The depth of poverty is estimated by the poverty gap ratio. The poverty gap ratio can be defined by the average distance below the poverty line as a proportion of that line, where the average is formed over the entire population, counting the non-poor as having zero poverty gaps. Thus the sum of poverty gaps (aggregated across all individuals) reflects the minimum amount of consumption that needs to be transferred to bring all the poor up to the poverty line. The square of the poverty gap measures the severity of poverty (Chaubey, 1995). The paper estimated incidence and intensity of poverty before and after OOP for health care.

Household consumption data derived from NLSS includes food expenses and home production (the value of goods consumed from home production, in addition to expenditures incurred through market purchase); Nonfood expenditure and inventory of durable goods (non-food consumption, "use values" of consumer durables rather than the actual expenditures on such items, housing expenses, in the form of rent (actual for tenants and imputed for owner-occupiers) and payments for utilities (e.g. electricity, water)(CBS, 2011a).

Chronic and acute illnesses data are also available in the survey data.Households were asked whether they had chronic illness or not within the last 12 months.Chronic illness is a long-term suffering. Chronic illness includes the illness that is occurred due to oldness, bad consumption behaviour, and tobacco and alcohol consumption such 
as heart disease, cancer, diabetes, liver problem among other. Household member may have one or more chronic illness. If they have more than one chronic illness, major one is included as chronic illness. Cost of chronic illness includes cost of medicine and health care (CBS, 2011a).

Acute illness and injuries are defined as sickness (other than chronic illness) and injuries withinthe last 30 days at the time of enumeration. Health care cost includes cost of diagnosis and health servicesand cost of medicine for illness and injury for last 30 days. Data related to household consumption and health care payment and other information were extracted from sections 5,6 and 8 of the questionnaires of NLSS 2010/11(CBS, 2011a). All data were managed, cleaned, normalized to common time reference and verified with summary results and poverty statistics published by CBS(CBS, 2011a).

\section{RESULTS}

\section{Cost of Illness}

The results from the survey data suggested that out of total population, the incidence of chronic illness was 11.7 per cent. Similarly, the incidence of acute illness was 20 per cent. Chronic illnesses are particularly related to non-communicable diseases and acute illnesses indicate communicable diseases and general illness. The categorizations of diseases are based on self-reported by the households.

Figure 1: Average Cost of Acute Illness and Injury

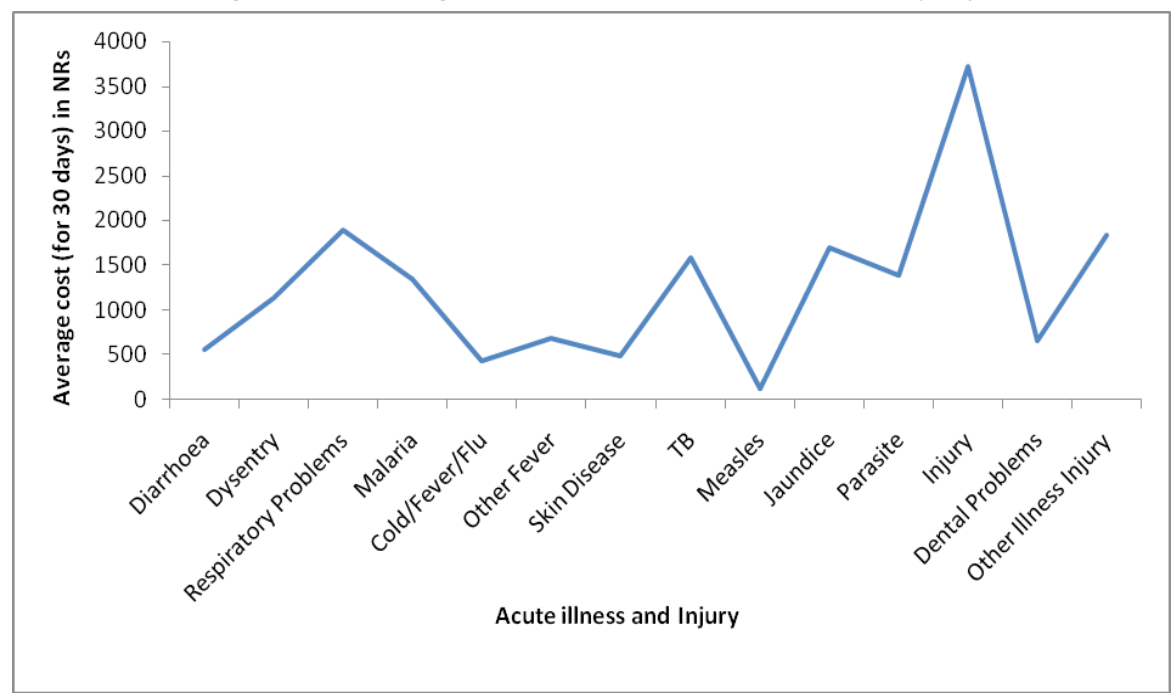

Source: Author 
Figure 1 exhibited diseases wise OOP for health care. Most of health cares are provided in subsidized prices in public providers. Market prices for health care are applied in the private providers. Costs of health care vary with different illness and injury. Injury accounts higher cost of care based on expenditure on last 30 days, which is Nepalese Rupees (NRs) 2727.

Similar to trends of acute illness, costs of health care for chronic illness vary widely from 1 thousand two hundred Nepalese Rupees (NRs) to 22 thousand NRs as reported by households. As suggested by the results, health cares related to heart condition, cancer, kidney/ liver diseases, diabetes and among others are costly than others (figure 2).

The share of total costs by consumption quintile is depicted in figure 3. As expected, the share of total costs is low for lowest quintile and high for richest quintile. The lines in the figure 4 have positive slopes, with indicating share of the total costs is increasing from lowest quintile to richest quintile. For the poorest quintile, cost of injury is higher than costs of acute and chronic illnesses; however, costs of chronic illness are higher for richest quintile.

Figure 2: Average Cost of Chronic Illness

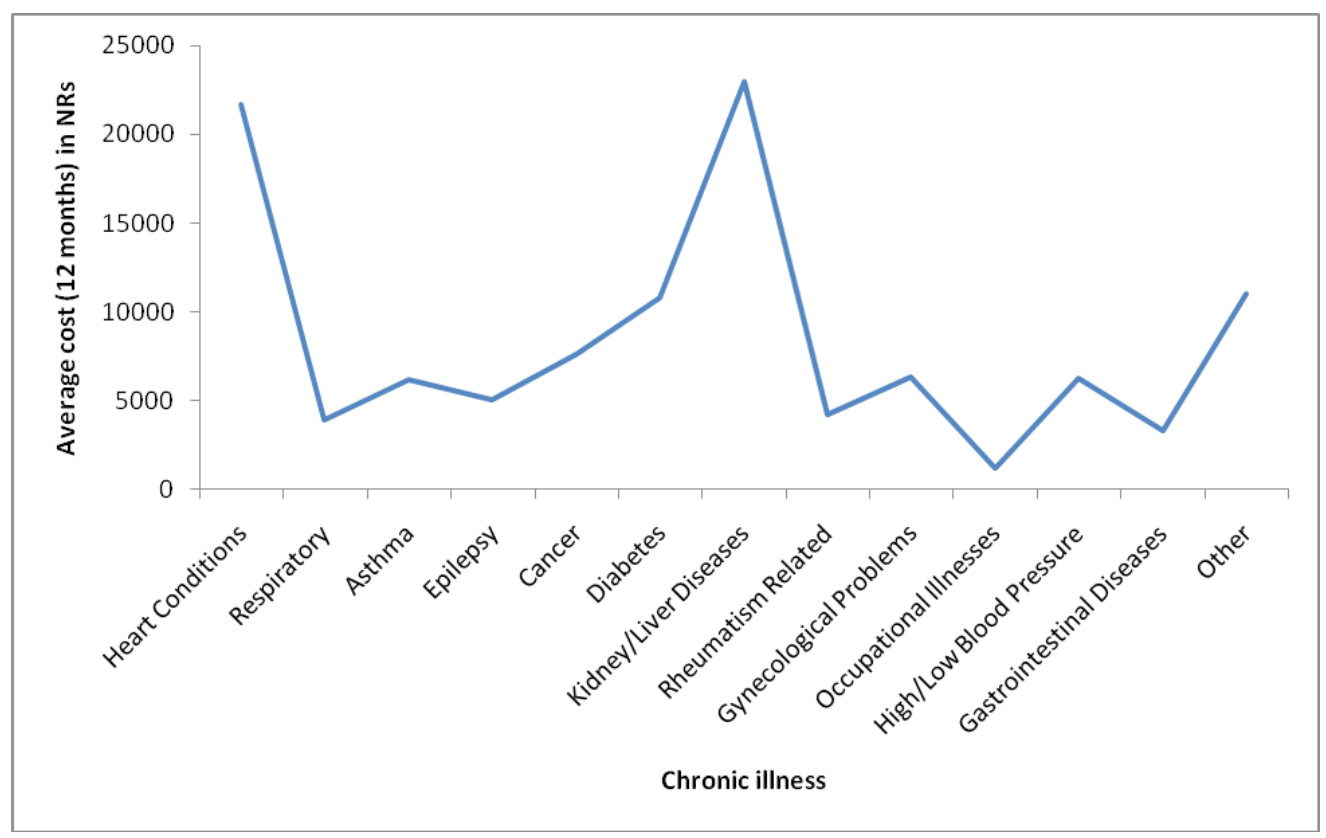

Source: Author 
Figure 3: Share of Total Costs by Consumption Quintile

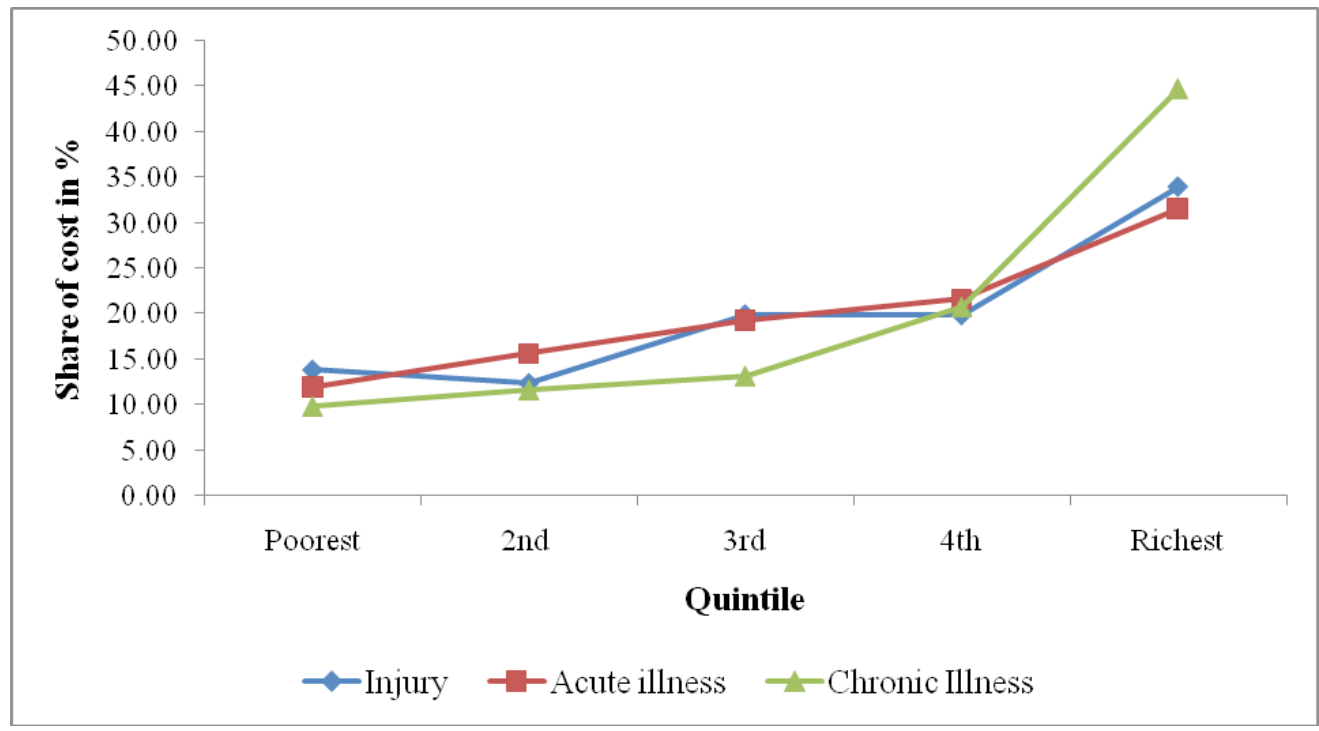

Source: Author

The Pen's Parade chart illustrates how the people can fall below poverty line due to OOP for health care. In this chart, household per capita consumption and national poverty line are measured in the y-axis. Cumulative proportion of population ranked by household consumption per capita is presented in $\mathrm{x}$-axis. The charts plot household pre- OOP for health care and post- OOP for health care, consumption per capita on $y$-axis against the cumulative percentage of households ranked by pre-payment consumption x-axis. The y-axis of the "paint-drops" shows household consumption net of OOP for health care. This shows how the households are pulled below the poverty line by such OOP for health care. 
Figure 4: Illustration of the Effects of OOP Health Payment on Pen's Parade (Injury)

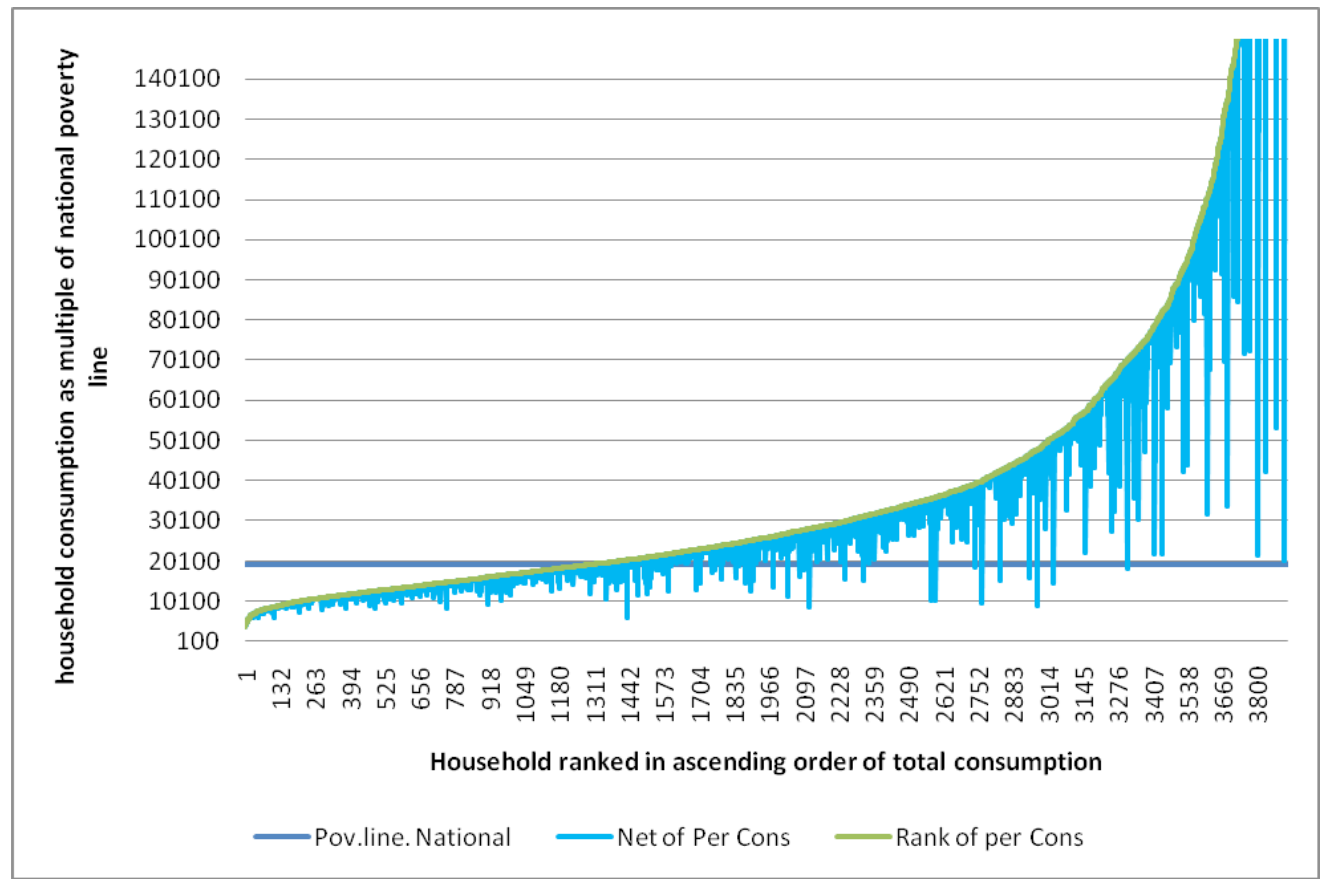

Source: Author

\section{Incidence of Poverty}

Using national poverty line for per capita consumption, 25.2 percent is incidence of poverty in Nepal for 2010/11. The estimated poverty based on per capita consumption before netting out OOP for health care is equal to official poverty incidence. The estimated poverty based on per capita consumption after netting out OOP for health care should be higher than official poverty incidence. The difference between poverty estimates derived from per capita consumption before and net of OOP for health care provides the poverty impact of such payments.

The dotted line in figure 5 indicates the incidence of poverty before netting out the health care costs from per capita consumption, that 25.2 per cent. After netting out the health care costs by illness category (or disease category) from per capita consumption, poverty incidences were increased, as indicated in figure 5. The distance between the dotted line and solid line gives the underestimated poverty rate. In other words, 
the difference reveals impoverishment impact of disease wise OOP for health care. Impoverishment impacts of diseases in term of incidence of poverty vary between 0.0001 to 1.44 per cent.

Figure 5: Poverty Incidence before and after Netting out the Health Care Cost (Acute Illness and Injury)

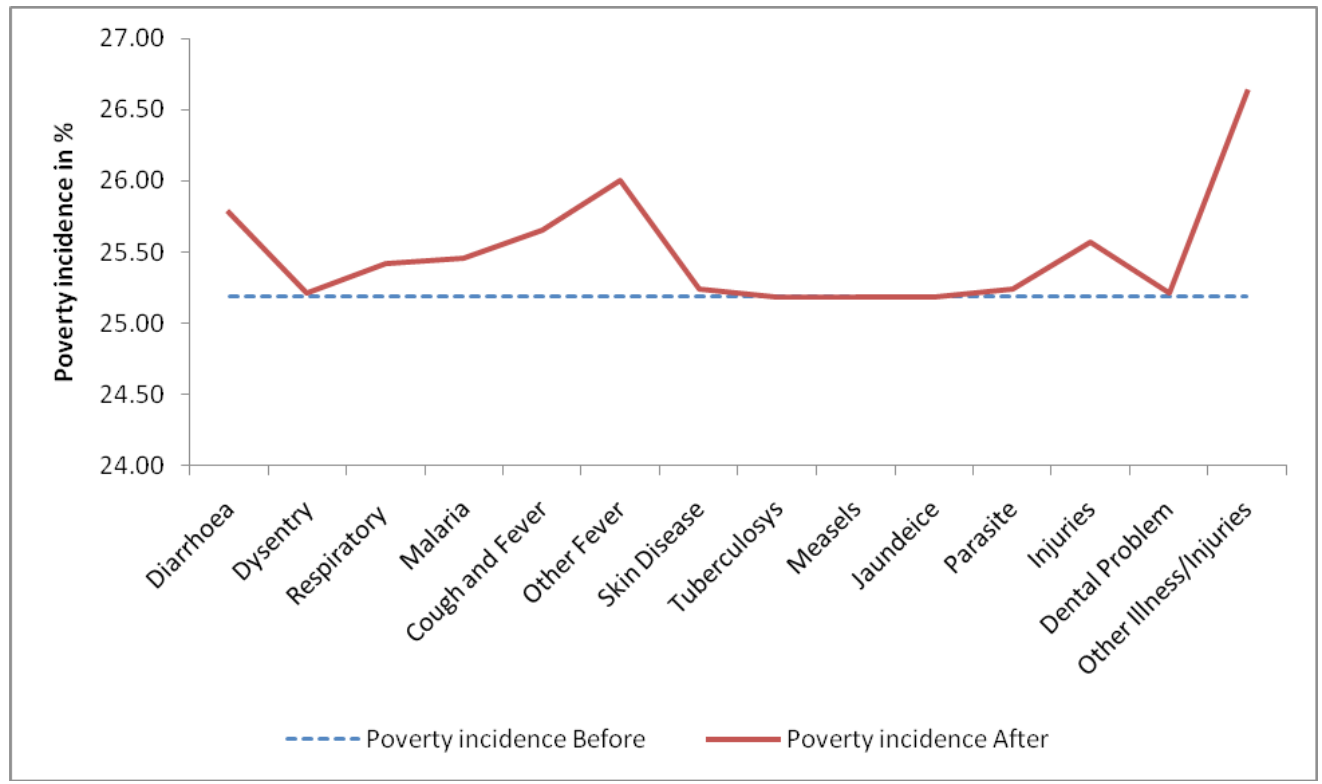

Source: Author

Similar to figure 5, figure 6 exhibits the impoverishing impact of acute illness. The distance between solid line and dotted line indicate incidence of underestimated poverty rate or impoverishment impact of chronic illness. Coinciding two lines in figure 6, indicates no impoverishment impact of concerned illness. The incidences of poverty due to chronic illness vary between 0.001 to 0.38 per cent. 
Figure 6: Poverty Incidence before and after Netting out the Health Care Cost (Chronic Illness)

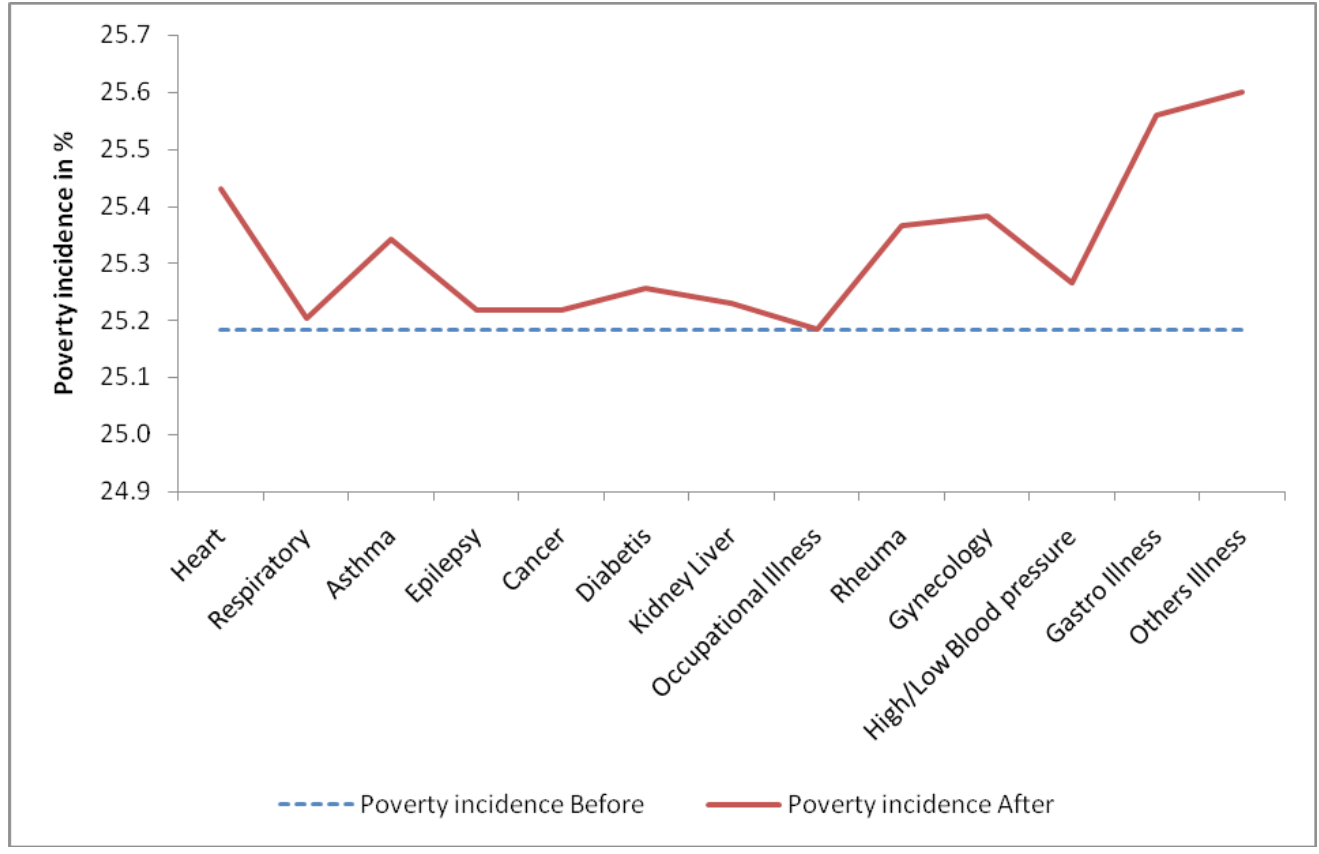

Source: Author

Impoverishment impacts of OOP for health care by disease categories in terms of incidence of poverty are shown in figure 7. These incidences indicate impoverishment impact of diseases. For example, additional 0.27 per cent individuals are pushing below poverty line due to malaria care. Malaria care is provided at free of cost at public health providers; however, malaria care can be treated in private providers as well. Some of the health care costs do not lead to impoverishing, for example, measles, TB and jaundice.Medical expenditures of most of the diseases are impoverishing. Nonpoor individuals are pushing below the poverty line due to medical expenditures. Medical expenditure of diarrheal diseases causes additional 0.59 percent individuals to fall below poverty line. Altogether, impoverishment impact of OOP for health care for all diseases was found almost 4 percent. This indicates that almost 4 percent poverty is underestimated in Nepal. 


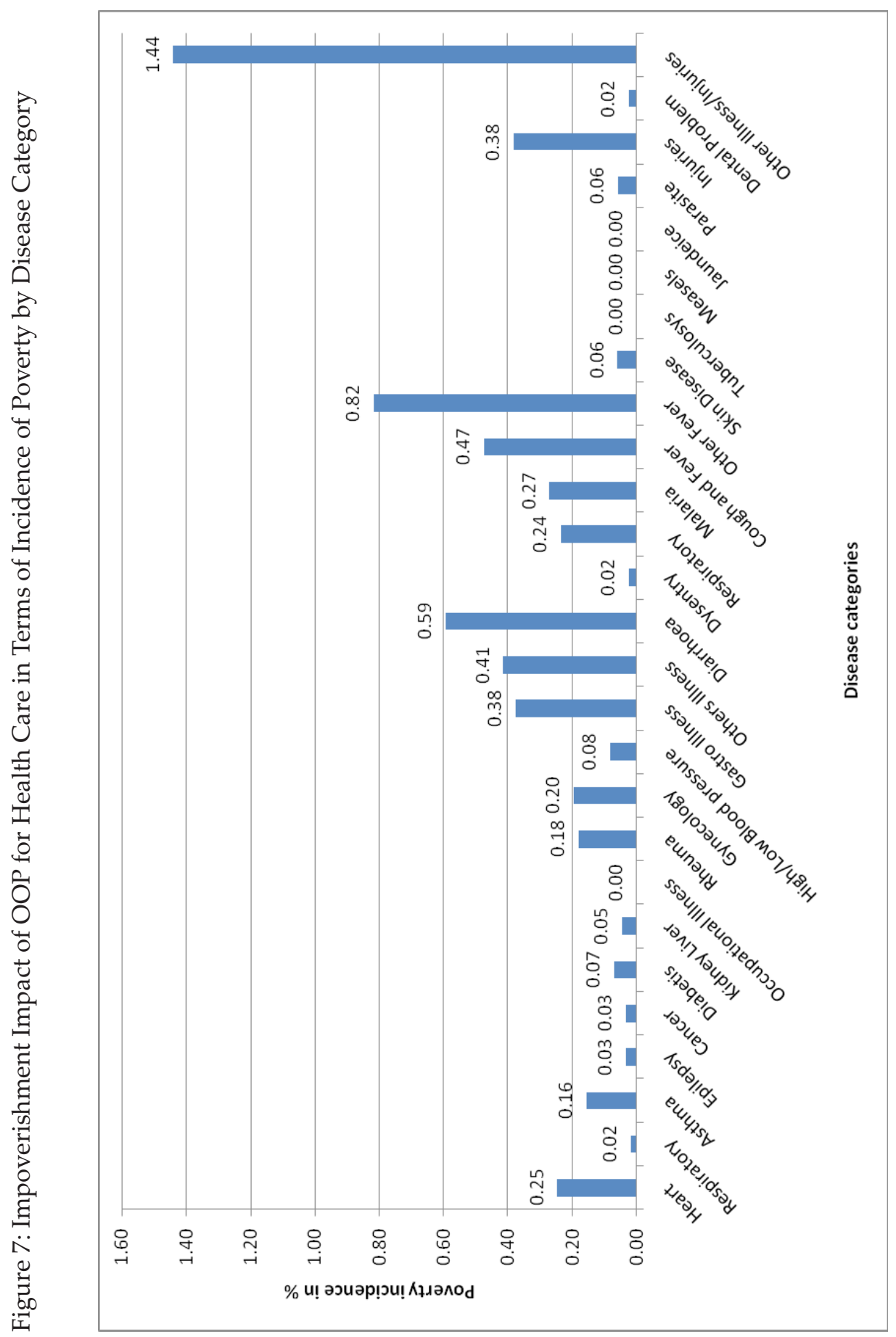


As shown in figure 8 , there is a positive association between average OOP for health care and impoverishment impact of illness. Higher average costs of illness leads to higher incidence of impoverishment impact. It doesn't mean that all higher costs of medical care are impoverishing. Very rich people can pay higher amount of money for medical care; however, they may not fall below poverty line. Therefore some of the non-poor may not face impoverishment impact due to OOP for health care.

Figure 8: Relationship between Average Cost and Incidence of Poverty

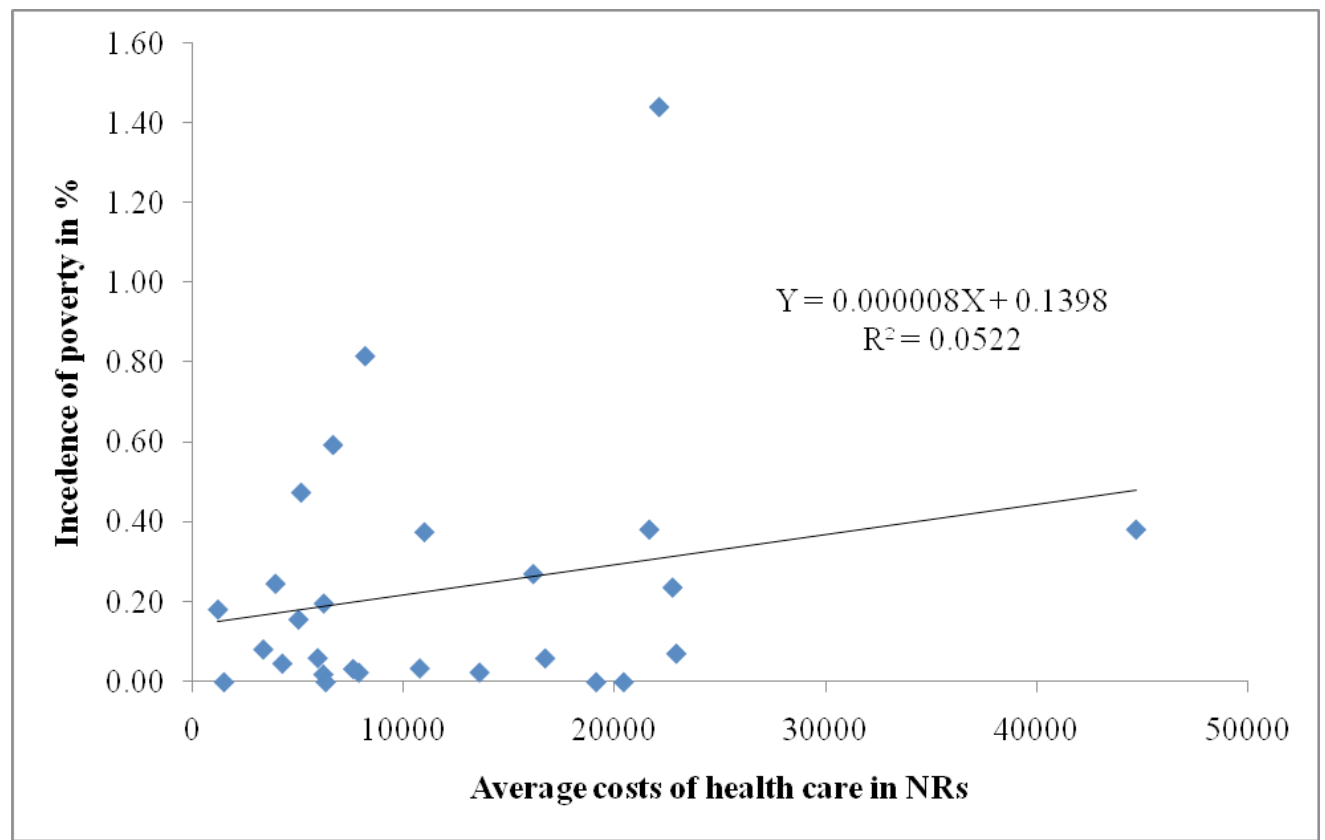

Source: Author

\section{Intensity of Poverty}

Incidence of poverty estimates the percentage of population that lives below the poverty line. OOP for health care affects the poverty gaps. The average distance from the poverty line may increase due to OOP for health care. Poverty gap is an important policy instrument. Poverty gap is the average shortfall of the total population from poverty line. It is assumed that non-poor have zero poverty gaps. As mentioned in the methodology section, acute illness and injury related cost data were based on within the last 30 days. Therefore, poverty was estimated using monthly poverty line income that is; annual poverty line income (NRs 19261) is divided by 12 . The dotted line in figure 8 indicates that the average poverty gap is almost 85 NRS (for a month) based 
on official poverty measurement. Solid line indicates an increase in poverty gap after incorporating health care cost. Similarly, in figure 9, the difference between dotted line and solid line indicates poverty gaps due to chronic illness. The poverty gaps measures pushing the poor individual into further poor. Impoverishment impact can be seen in intensity of poverty. Although health care costs for TB and jaundice don't cause poverty incidence; but they cause intensity of poverty. It means already poor individuals are pushed into further poor (marginal poor) due to health care costs.

Figure 8: Average Poverty Gap due to Acute Illness and Injury

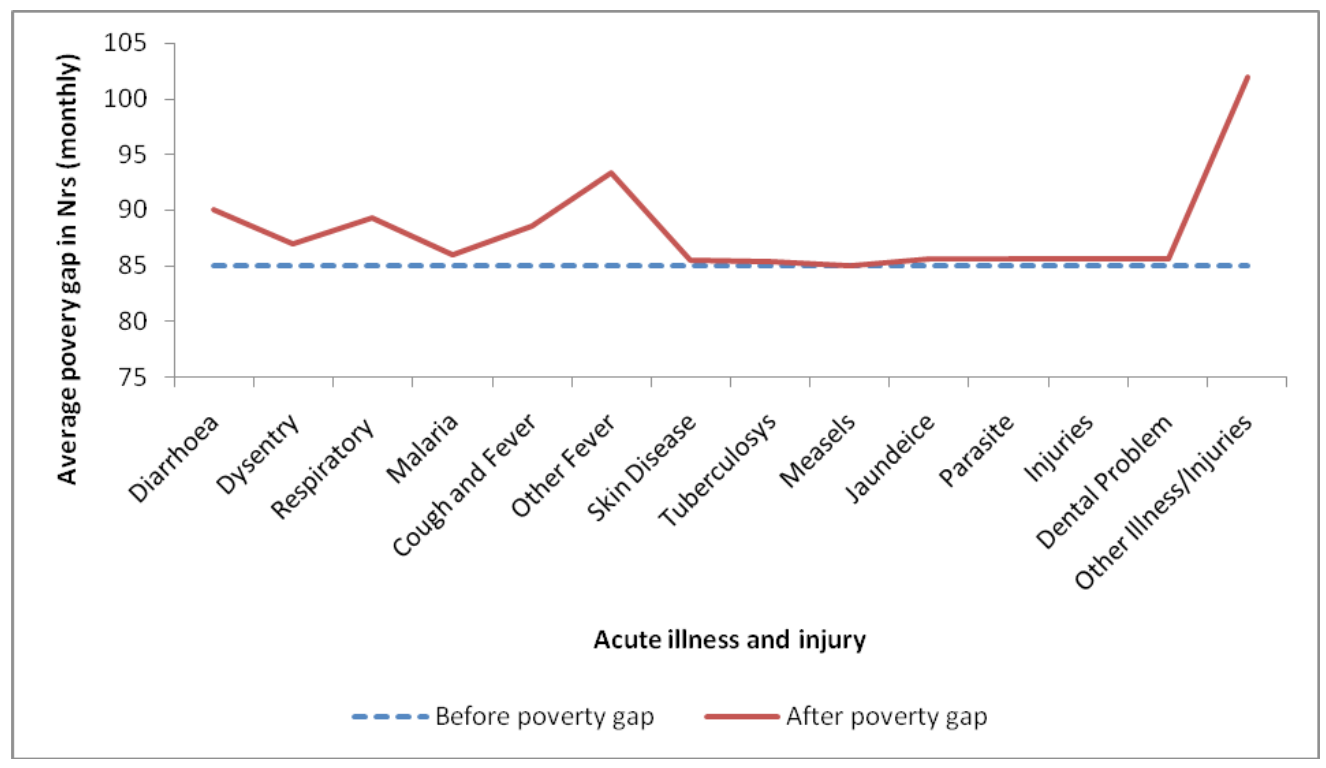

Source: Author 


\section{Figure 9: Average Poverty Gap due to Chronic Illness}

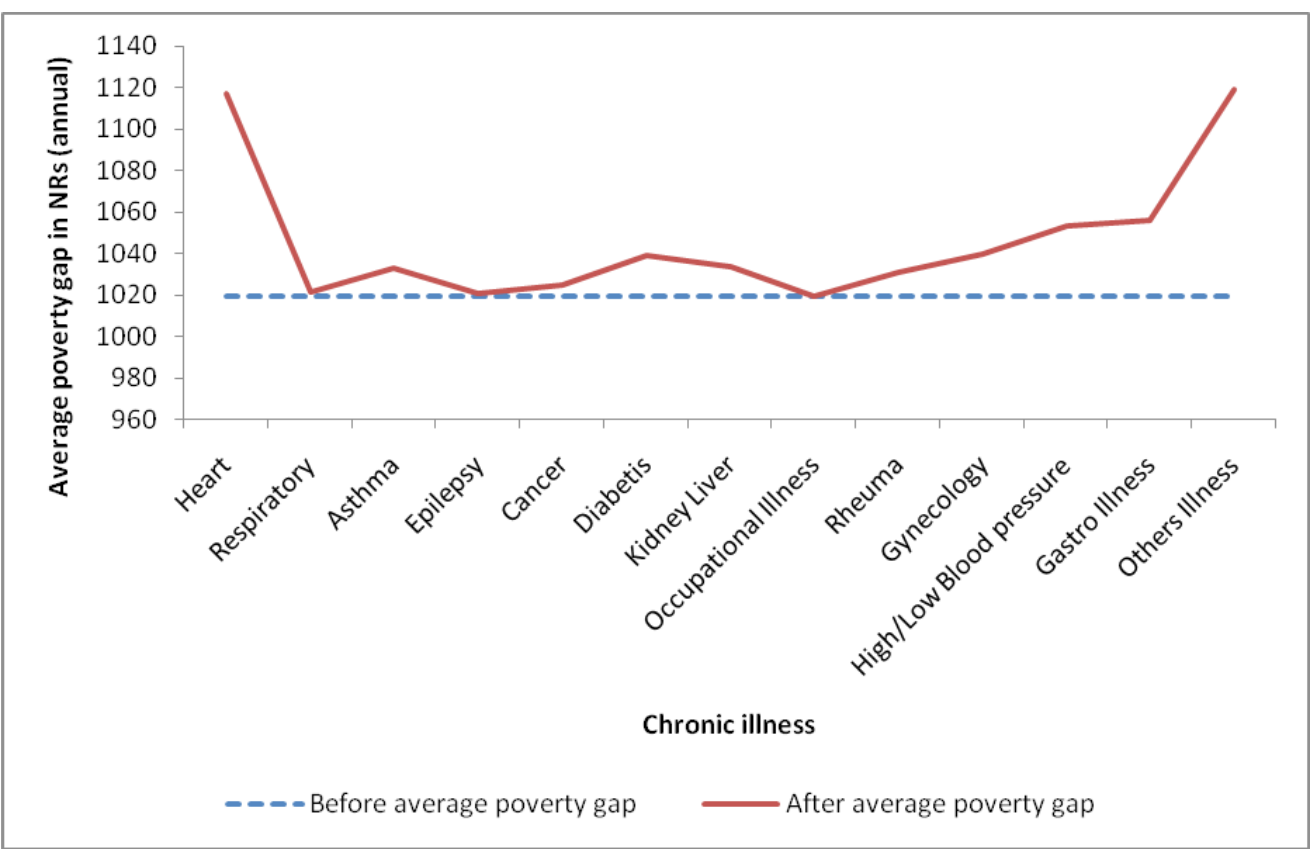

Source: Author

The figures 8 and 9 demonstrate the poverty gaps in term of monetary value. Poverty gap ratio rather than monetary amount is generally used to measure the poverty gap. It allows to comparing the poverty gaps with other countries. The poverty gap ratio is defined by the average distance below the poverty line as a proportion of that line, where the average is formed over the entire population. Estimated poverty gap ratio (or intensity of poverty) before netting out OOP for health care from per capita consumption (or official poverty gap ratio) is 5.43 per cent. This poverty gap is underestimated by 0.29 percentage point. The figure 10 suggests that health care costs for all of the diseases are impoverishing in terms of intensity of poverty. In other words, all diseases are responsible to push the poor people into marginal poor. It will create chronic poverty. The result indicates that chronic diseases make chronic poverty in low income country. 


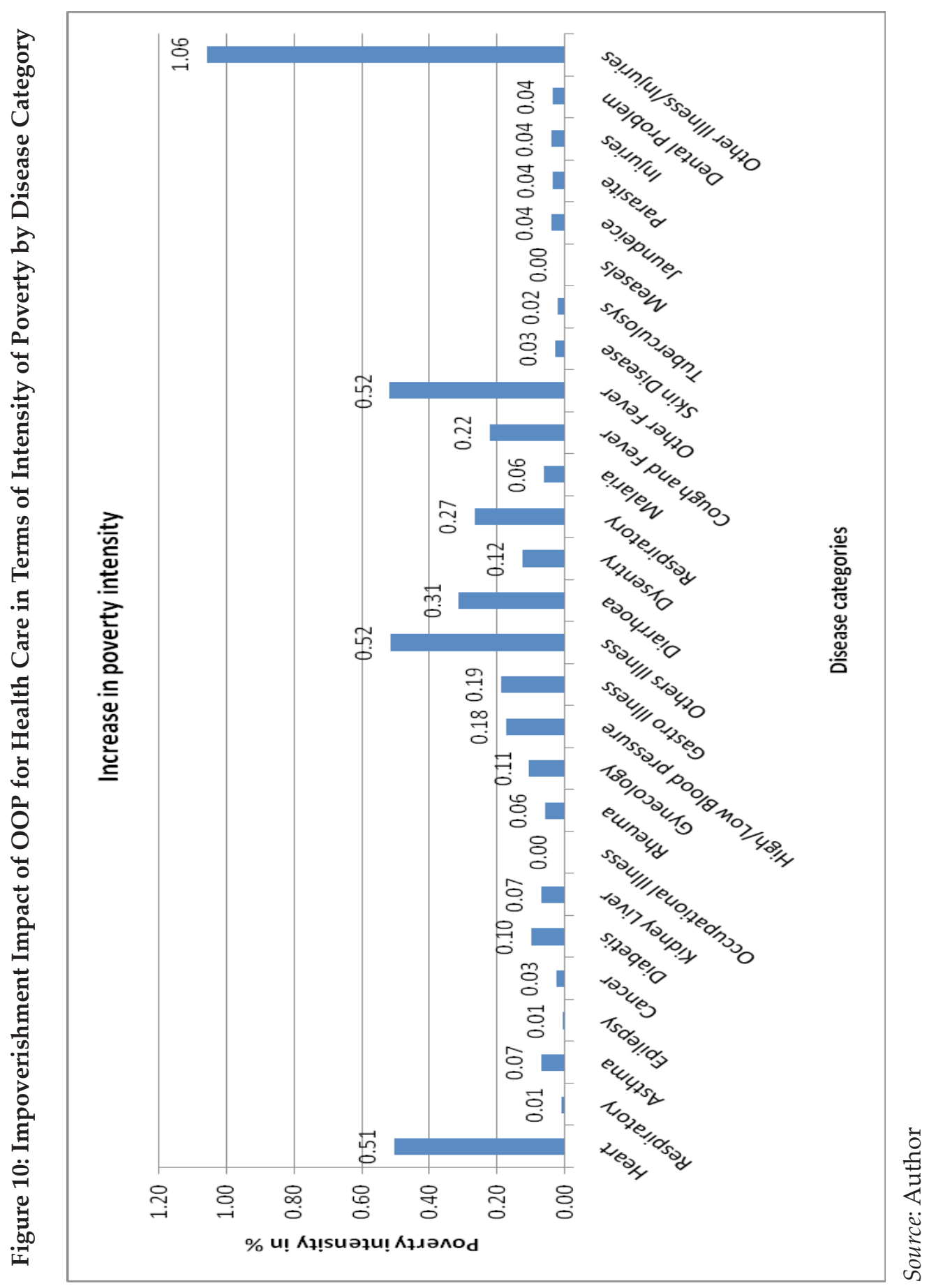




\section{DISCUSSIONS AND CONCLUSIONS}

No doubt, basic health care is basic need as food, shelter etc; however, current practice of measuring poverty does not the health care cost while estimating the poverty statistics. Without adjustment of OOP for health care, poverty indicators are underestimated consequently the coverage of the programmes is not sufficient. Poverty is local as well as national public goods that have negative externalities. Poverty begets poverty. Consequently, there may be policy uncertainty. Target policy to reduce the poverty intensity and incidence may not produce desired results. At least, policy makers should know the underestimated (hidden) poverty due to current practice of estimating poverty indicators in Nepal.

The paper estimated the hidden poverty through the difference between poverty estimates derived from household per capita consumption without netting OOP for health care and with netting OOP for health care using official poverty line. The results suggest that incidence of poverty is underestimated by almost 4 percentage point and intensity of poverty (poverty gap ratio) is underestimated by 0.29 percent based on Nepal living standard survey data 2010/11. Impoverishment of impact of costs of health care in terms of incidence poverty for Nepal was 1.75 per cent in 1995/96. Similarly, in terms of intensity poverty was 1.15 percent (Van Doorslaer et al, 2006). Hamid et al conducted a study in Bangladesh and found that OOP for health care annually pushed $3.4 \%$ households into poverty. Due to medical cost for chronic illness, impoverishment impact was 4.65 per cent in terms of incidence poverty. However, this study suggested that the intensity of impoverishment was the largest among the hospitalized patients. Adhikari et al (2009) found that direct costs of hospital based treatment of Kala azaar caused more than $20 \%$ individuals to fall below the poverty line.

The living standard survey data of Nepal does not allow to categorizing cost of care into inpatient and outpatient. Therefore, it is not possible to estimate the impoverishment impact based on hospitalized care. The survey focused on living standard related indicators; therefore, details of disease category were not available. Costs related to co-diseases may be over or underestimated; therefore, the results presented here are indicative.Poverty, health and public investment/expenditure in healthcare emerge as being very closely correlated. The results of this paper inform the policy-makers underestimated poverty due to not including basic health care while estimating official poverty statistics.

The paper concludes that health care expenditures are impoverishing; however, such impoverishment is not captured by the current approach of measuring of national 
poverty rate. Medical expenditures are non-discretionary and it allows to estimate hidden poverty rate. This study indicates that both incidence and intensity of poverty.

\section{References}

Adhikari, S.,R., Maskay, N.M., \& Sharma, B.P. (2009). Paying for hospital -based care of Kala-Azar in Nepal: Assessing catastrophe, impoverishment and economic consequences. Health Policy and Planning, 24, (2), 129-139.

Anand, S., Segal, P. \& Stiglitz, J. E. (2010). Debates on the measurement of global poverty. Oxford University Press.

Central Bureau of Statistics (CBS). (2011a). Nepal living standards survey 2010/11: Statistical report volume one and two. Central Bureau of Statistics, National Planning Commission Secretariat, Government of Nepal.

Central Bureau of Statistics, (CBS). (2011b). Poverty in Nepal 2010/11. National Planning Commission Secretariat, Government of Nepal.

Chaubey, P. K., (1995). Poverty measurement: Issues, approaches and indices. New Delhi, India: New Age International (P) Limited Publications.

Hamid, S. A., Ahsan, M.S., \& Begum, A. (2014). Disease-specific impoverishment impact of out-of-pocket payments for health care: Evidence from rural Bangladesh Appl Health Econ Health Policy, 12 (4), 421-33. doi: 10.1007/s40258-014-0100-2.

Nepal National Planning Commission (NPC). (2017). National review of sustainable development goals. Singhdurbar, Kathmandu: Government of Nepal, National Planning Commission.

O'Donnell, O., van Doorslaer, E. Wagstaff, \& A. Lindelow, M. (2008). Analyzing health equity using household survey data: a guide to techniques and their implementation The International Bank for Reconstruction and Development .

Saksena, P., Hsu, J., \& Evans, D. (2014). Financial risk protection and universal health coverage: Evidence and measurement challenges. PLoS Med, 11(9), e1001701. doi:10.1371/journal.pmed.1001701.

Short, K., \& Garner, T. (2002). Experimental poverty measures: Accounting for medical expenditures. Monthly Labor Review, 125, 3-13.

United Nations (UN). (2015a). Transforming our world: The 2030 agenda for sustainable development. Resolution adopted by the General Assembly on 25 September 2015, Seventieth session Agenda items 15 and 116, UNHQ. 
United Nations (UN). (2015b). Integrating the three dimensions of sustainable development: A framework and tools. United Nations publication ST/ESCAP/2737 Environment and Development Division United Nations Economic and Social Commission for Asia and the Pacific United Nations Bangkok 10200, Thailand.

Van Doorslaer, E. O'Donnell, O. Rannan-Eliya, R.P., Somanathan, A., Adhikari, S.R., Garg, C.,C., et al.(2006). Effect of payments for health care on poverty estimates in 11 countries in Asia: an analysis of household survey data. Lancet 2006, 368, 1357-64. 